\title{
PERFORMANCE MEASUREMENT SYSTEM: A BENCHMARKING SYSTEM OF THE SLOVENE AND CROATIAN HOTELS
}

\author{
Gordana Ivankovič ${ }^{1}$ (D) \\ Mateja Jerman²
}

DOI: https://doi.org/10.31410/tmt.2020.317

\begin{abstract}
The paper presents a performance measurement system that was developed with the aim to provide a useful benchmarking tool for Slovene and Croatian hotels. Financial results of Slovene and Croatian hotels show that there is room for improvements. That is why the necessity to develop a performance measurement system emerged. The paper presents the development process of this performance measurement system and the theoretical background of selected measures that are included in the system. This system includes both financial and non-financial indicators of performance. Financial indicators are based on USALI standards for the lodging industry, while non-financial indicators were developed based on a literature review. Non-financial indicators include information about guests, employees, and corporate social responsibility. The presented performance measurement system enables hotels to analyse their financial performance on a daily level, while non-financial indicators can be evaluated on a monthly and annual basis.
\end{abstract}

Keywords: Hotel industry, Performance analysis, Benchmarking analysis, Slovenia, Croatia.

\section{INTRODUCTION}

$\mathrm{T}$ he purpose of this paper is to present a performance measurement system that was developed with the aim to provide a useful benchmarking tool for Slovene and Croatian hotels. The necessity of having this kind of system emerged since to date in both countries a system that would facilitate a benchmarking analysis of hotel companies was not yet in use. Since the hotel industry is an important branch in both countries, the idea to develop a performance measurement system emerged. Indicators included in the developed performance measurement system are grounded on the literature review and $\mathrm{USALI}^{3}$ standards.

Direct and indirect effects of tourism on the Slovenian GDP in 2019 were 9.9\%, while the share of employees working in this industry in relation to total employees amounted to $10.3 \%$ (WTTC, 2020). Tourism in Slovenia is also an important export activity, as in 2019 it reached $€ 177$ million, which represents $6.2 \%$ of total exports. Within the Standard Classification of Activities, the most important tourist activity in terms of generated revenues and number of employees in Slovenia are accommodation and food service activities (AJPES, 2020). 2019 was the sixth consecutive record year for the Slovene tourism industry. The number of tourist arrivals amounted to 6.2 million and, overnight stays to 15.7 million (STB, 2020). In contrast, data regarding financial performance show that the hotel industry sector has not been successful. On average Slovene hotel, companies do not add value for their owners (Stubelj and Jerman, 2019).

$1 \quad$ University of Primorska, Faculty of Tourism Studies - Turistica, Obala 11a, 6320 Portorož, Slovenia

2 University of Primorska, Faculty of Management, Cankarjeva 5, 6000 Koper, Slovenia

3 USALI - Uniform System of Accounts for Lodging Industry (2019) is a standard system of accounting reports on the level of a unit - hotel, which was developed under the influence of American international hotel chains. The first edition of the uniform report system was published in 1926. 
The latest data for Croatian tourism show that the number of tourist arrivals was increasing from year to year and reached a total number of 19 million arrivals in 2019. In the same year, the number of tourist overnight stays reached 91 million. Hotels recorded $22.8 \%$ of total tourist overnight stays. In 2019, the share of employees working in hotels and restaurants in relation to total employees amounted to $8.2 \%$. In 2019, the share of the tourism industry represented approximately $19.5 \%$ of Croatian GDP (Ministry of Tourism Republic of Croatia, 2020).

Since data show that the hotel industry is a very important sector for the creation of the Slovenian and Croatian GDP, the idea of having a performance measurement system that could provide prompt (up to date) information about the performance of companies operating in this industry emerged. The purpose of the paper is to present this performance measurement system and its theoretical background.

\section{DEVELOPMENT OF A PERFORMANCE MEASUREMENT SYSTEM FOR SLOVENE AND CROATIAN HOTELS}

The idea was founded by the Operational program Slovenia-Croatia. The project was entitled "Benchmarking of Croatian and Slovenian hotel sector: an instrument to increase competitiveness and entrepreneurship development". "The main objective was to create dynamic cross-border cooperation between hotel enterprises aiming to enable comparison of their businesses in order to increase the level of their economic development and tourism entrepreneurship in general. To achieve its purpose, the project aimed to:

- Develop a joint methodology of financial and non-financial indicators for performance analysis;

- Enable a benchmarking analysis between hotels;

- Develop software that would enable performance analysis on a daily basis.

In Slovenia, the principal obstacles preventing the possibility to perform a benchmarking analysis of hotels were/are as follows. Hotels that are part of a larger hotel group do not report separately for the purpose of external financial reporting. Thus, financial reports are often prepared for the group and not for a single entity. These reports do not allow management to make comparisons with the results of competitors. Moreover, several hotels are owned by companies that do not operate only in the hotel industry. If only consolidated financial reports are prepared for the group of companies, the results cannot be used for making comparisons. Secondly, the reports are not prepared in accordance with the widely used standards for the lodging industry USALI. They are prepared in accordance with the national accounting standards (Slovene Accounting Standards). Slovene hotels rarely implement the standards for the hotel industry. Finally, financial reports for the accounting period are publicly available only several months after the period when business events occurred, thus the analysis of this kind of data is not timely.

That is why a system enabling hotel management to perform a benchmarking analysis with competitors was needed. The project aimed to develop a methodology that includes both finan-

$4 \quad$ There were four partners in the project. The leading partner was the Faculty of Tourism and Hospitality Management from Opatija (Croatia), which has extensive experience with similar projects. The second partner was the Faculty of Tourism Studies from Portorož (Slovenia), which has extensive experience from the field of hotel industry analysis. Finally, the remaining two partners were organizations that have an important influence in the field of hospitality tourism in both countries, i.e. Tourism and Hospitality Chamber of Slovenia and Association of Employers in Croatian Hospitality (UPUHH). The latter is the leading professional association in the hotel industry, and hospitality in general, in Croatia, focusing on long-term development goals in the hospitality sector. 
cial and non-financial indicators. The development process of this performance measurement system required a theoretical review of the literature and best practices. Based on the literature review, the proposed list of indicators for the performance measurement system was prepared. The list of indicators was presented to the hotel representatives. Project partners organized several workshops in each of the two countries involved in the project. At the workshops, all the proposed inputs were presented. Based on the comments and suggestions of hotel representatives, the list was upgraded. Thus, a list of the most important indicators was prepared. The paper will now present the performance measurement system developed for the purpose of benchmarking analysis and continue with the theoretical background that supports the selections of indicators included in the presented performance measurement system.

\subsection{Indicators used in the performance measurement system}

This performance measurement system is composed of two major parts, i.e. the part that includes financial data and the part that includes mainly non-financial data. To understand the performance measurement system that was developed and is used by hotels, both the financial and non-financial indicators will be presented. The first part of the system includes financial data about hotel operations. The methodology is based on USALI standards (2019).

\subsection{Financial indicators included in the performance measurement system}

The following inputs have to be uploaded on a daily basis to enable daily comparisons of results between different hotels. The required inputs for an individual hotel daily are:

- General information about facilities: number of available rooms, number of rooms occupied.

- Number of overnight stays and guests (divided into domestic and foreign guests).

- Information about revenues: revenues from the accommodation, revenues from food and beverages, revenues from wellness/spa, revenues from other business departments.

Based on these inputs on a daily level, hotels have the chance to make a comparative analysis of the following indicators (outputs): rooms' occupancy rate, average room rate, revenues per available room, total revenues per available room, total revenues per overnight stay and structure of revenues. Hotels have the chance to monitor revenues by the segment on a weekly level.

On the monthly level hotels must provide data about generated revenues and costs, number of guests and guest structure. The required inputs for an individual hotel monthly are:

- Information about revenues: revenues from the accommodation, revenues from food and beverages, revenues from wellness/spa, revenues from other business departments, revenues from rental and other income.

- Cost information: direct costs of business departments (accommodation, food and beverages, wellness/spa, other departments).

- Direct labour costs and other direct costs of business departments (accommodation, food and beverages, wellness/spa, other departments).

- Unallocated indirect costs: administrative and other indirect costs, marketing and sales, investment and current maintenance, energy, fixed (uncontrollable) costs.

On a monthly level, hotels have the possibility to receive the following indicators: rooms' occupancy rate, average room rate, revenues per available room, total revenues per available room, 
total revenues for the segment of lodging, an average rate of half board packages, share of direct cost in revenues (separately for each department), share of direct cost in total revenues (by business department), share of indirect cost in total revenues, share of gross operating profit in revenues and gross operating profit per occupied room. Moreover, hotels receive information about revenues (by departments), direct costs of business departments, sum of contribution margins to cover business departments, unallocated general costs - controllable, gross operating profit (GOP), fixed costs - uncontrollable, EBITDA (earnings before interests, taxes, depreciation, and amortisation), depreciation and EBIT (earnings before interests and taxes). These data enable a hotel to perform revenue management and cost control.

Apart from financial indicators, the system also enables hotels to compare non-financial indicators. Non-financial indicators are monitored mainly on a monthly and/or annual basis.

\subsection{Non-financial indicators included in the performance measurement system}

The second part of the presented performance measurement system includes mainly non-financial information about hotel performance. It is divided into three segments of information: information about guests, employees, and corporate social responsibility. Hotels are required to provide the following information about their guests: number of arrivals and overnight stays, share of different target groups, share of regular hotel guests, structure of domestic and foreign guests, country of origin of foreign guests, methods of hotel reservation and guests' satisfaction.

Apart from data regarding the characteristics of guests, the hotels are required to provide data about employees. The information about employees is separated into two parts. The first part concerns financial data about employees, while the second includes a questionnaire about their satisfaction. Employees' satisfaction is measured with selected questions that derive from the literature review.

The area of corporate social responsibility (CSR) covers three dimensions, i.e. local community, environment and marketplace policy. The dimension of human capital is covered separately from CSR.

Since the development of this performance measurement system was developed based on a literature review and best practices, hereinafter we present the theoretical background. The theoretical background concerns non-financial indicators covering the aspect of guests, employees, and corporate social responsibility. ${ }^{5}$ Financial data (inputs) are based on USALI standards (2019).

\section{THEORETICAL BACKGROUND OF THE DEVELOPED PERFORMANCE MEASUREMENT SYSTEM - INFORMATION ABOUT GUESTS, EMPLOYEES AND CORPORATE SOCIAL RESPONSIBILITY}

Hotel enterprises have unique operational characteristics, as they bring together many activities that are essential for guest satisfaction. Corresponding particularities are, according to several authors (Jones and Lockwood, 1998; Harris, 1992; Chibili, 2016): fixed facilities, direct contact with guests, volatile customer demand, critical human factor, and high fixed capital costs.

A high level of competitiveness is typical for the business environment in the hotel industry. It requires that management continuously adjusts to guest needs that are essential for the good performance of an individual hotel. A developed MAS (management accounting system) is

5 The aspect of employees is monitored with both, financial and non-financial data. 
useful in meeting the needs of guests and furthermore in achieving business objectives (Damonte et al., 1997; Chibili, 2016). Information of the MAS is required for high-quality decisions (Mia and Chenhall, 1994; Dopson and Hayes, 2016) and utilization of comparative advantages (Downie, 1997). That is why MAS has to provide the information required for management decision-making (Dent, 1996; Mia and Chenhall, 1994). The development of an adequate MAS has to be primarily grounded on business objectives and business strategies. In the continuation, crucial variables (to achieve the goals) have to be identified, i.e. critical success factors (CSF).

Since guests are the focus of hotel operations, we will first present the theoretical background used for the development of the performance measurement system in this area. It will be followed by the literature review of indicators concerning employees.

\subsection{Guest segmentation}

Market segmentation in the hotel industry is an important marketing tool that is essential for the success of the hotel (Ivankovič et al., 2015). Various authors similarly define market segmentation. Tranter et al. (2014) define market segmentation as the practice of dividing a market into smaller specific segments sharing similar characteristics. Market segmentation is an important marketing tool with which the company distributes the heterogeneous consumer market into smaller homogeneous groups or segments. Nickels and Wood (2000) highlighted four positive effects of market segmentation: the possibility of establishing more genuine and long-term relationships with key customers, improving the efficiency and effectiveness of marketing, a better understanding of the competitive marketing tools and faster adaptation to needs of customers.

In order to better understand the characteristics of different people, the market can be divided into groups that have common needs and distinct buying habits. Market segmentation is a necessary strategic measure for the best results. Since companies are not capable of operating on all markets, they must select target markets. The major traditional market segmentation variables, according to Forgacs (2010, p. 69-70) are geographic, demographic, psychographic and behavioural traits and price-sensitivity.

Polovitz (1996) defines different criteria for market segmentation in the hospitality industry. Guests must be divided by their demographical and psychological characteristics, meaning age, time of arrival, method of reservation, willingness to pay, different needs and other characteristics of their behaviour. A revenue manager should also distinguish price-sensitive guests from those who are not price-sensitive. These two basic groups call for different marketing and revenue management approaches (Forgacs, 2010).

Most often, the authors specify different approaches to segmentation (Tkaczynski et al., 2009):

1. Geographic - this segmentation classifies guest segments, arising from the same country, region or even continent.

2. Demographic - this segmentation considers sex, age, gender and other characteristics of singlehood guests (D’Urso et al., 2013). Tranter et al. (2014) lists also marital status, education, occupation, income, race, and religion.

3. Psychographic - people are classified according to their interests, mainly based on personality that affects a certain behaviour. Our inner self, according to psychographic theory affects the whole process of thinking and decision-making for the purchase of a service. 
4. Behavioural segmentation is based on certain situations and reactions of consumers shopping in the sales process. People have different patterns of behaviour, so the ones who have travelled together are usually the ones with similar habits (Kahreh et al., 2014).

Another distinction of a market segment is determined by the type of advertising. It is important to figure out which products increase guest satisfaction and which products are perceived as something necessary by tourists, without additional value (see Fuller and Matzler, 2007). Another question is what the target segment of guests is because the importance of different products varies from segment to segment. Based on this information the hotelier can develop products, from which they should stand out in the market and justify the price of services, and their advertising strategy (Fuller and Matzler, 2007).

\subsubsection{Market segmentation - guest usage segmentation}

Lewis and Chamber (1989) consider that usage segmentation is the most appropriate for the hospitality industry and covers a range of categories. Guests can be divided in accordance with their purpose of staying at the hotel. Frequency segments deal with usage regularity (loyalty of guests). Many hotels offer guest programs. These are designed to reward loyal patronage and induce repeat returns of guests (Tranter et al., 2014).

Timing depends upon different periods of visits. These depend on different days of the week, weeks, months, and seasons. Timing segmentation consists of low season and high season. It depends on what people seek (for example peace and rest, summer heat). Timing segments can also be based on the time the guest buys the service. For example, for some events or international conferences, the hotels are booked at least a year in advance (Lewis and Chambers, 1989).

\subsubsection{Market segmentation regarding the type of advertising}

Hotel offer does not only include a room but also various free or payable services (such as swimming pool, restaurant, bar, sauna), attractions, etc. These additional services can also be used for target segmentation, as something that sets a hotel apart from the competition. A hotel can also differentiate itself by providing healthy food, special sorts of food, natural and cultural attractions near the hotel, etc.

Online central reservation systems (that are connected into bigger global distributing systems) are becoming an increasingly popular method of advertising and distribution because, in addition to being very well known among the users and providing up to date and specific information, they also enable immediate reservation and purchase of hotel facilities. Both independent hotels and hotel chains rely on this method (Nemec Rudež, 2013).

Some hotels still put focus on advertising through specialized agencies, particularly hotels with a target segment of older guests (for example hotels with wellness facilities). But in general, the power of agencies is decreasing, as more and more people use online systems (Nemec Rudež, 2013).

\subsection{Employees - a critical success factor}

Jones (1995, pp. 163) has come across a discrepancy between the existing management accounting system and the requirements for information on different levels of accounting, originating 
from critical factors for achievement. Consequently, it has been drawn out that employees are the most important critical factor for achievement in most accounting systems of the hotel companies under study (Jones, 1995, pp. 163). The importance of human capital for future performance measurement was already pointed out by Kaplan and Norton (1992) with their Balanced Scorecard (BSC), where target priorities were divided into financial and non-financial targets (including fluctuation of employees). The empirical analysis of Slovene hotels showed that in order to increase competitiveness managers should focus much more on developing human capital (Nemec Rudež and Mihalič, 2007). The quality of personal services for individual guests and the preparation and implementation of services in hotels depend mostly on the employees. To that end, it is not surprising that hotels' employees most frequently represent the most important critical success factor.

The hotel industry in Slovenia has its unique work environment characteristics. It is denoted by low salaries, restricted opportunities for career progression, disadvantageous work times, discomfort in working conditions and a high degree of undeclared work. These are the reasons that lead to poor operational efficiency and, moreover, a high staff turnover (RNUST, 2009). Lower wages in the hospitality sector in comparison to other private sectors were already evidenced by Casado-Díaz and Simón (2016). They found that wage disadvantage for hospitality workers is particularly a consequence of lower educational qualifications (Casado-Diaz and Simon, 2016). The study of Arbelo et al. (2017) shows a positive correlation between accumulated experience or knowledge and efficiency, emphasizing the importance of employee training.

The research into human resources has demonstrated that the biggest weaknesses in the field of tourism (and hence also in the hotel industry) in Slovenia are (RNUST, 2009):

- the low level of knowledge,

- a gap between formal education and restricted practical qualifications in touristic enterprises,

- a gap between formal education and the needs of companies in practice and, finally,

- a decreasing interest in professions from the hotel industry.

Employee satisfaction is a central concern in the service industry in general and in hospitality in particular. Many studies found a positive relationship between employee satisfaction, customer satisfaction, and company performance (Matzler and Renzl, 2007). Employee satisfaction is typically viewed as a multidimensional construct. There exist several scales to measure satisfaction regarding several dimensions. Only satisfied employees can be effective and successful in the performance of their duties (Matzler and Renzl, 2007).

Since studies have demonstrated the link between employee satisfaction and guest satisfaction in the hotel industry, many companies monitor employee satisfaction and implement programmes to enhance the satisfaction and loyalty of the employees (Yee et al., 2008). Yee et al. (2008) found that employee satisfaction is significantly related to service quality and customer satisfaction, while the latter in turn influences firm profitability.

\subsubsection{Employee satisfaction and customer satisfaction}

Research on consumer psychology has shown that exposing customers to happy employees results in customers having a positive attitude towards a product. Likewise, research on organizational behaviour has revealed that the hostility of service employees has a direct impact on the 
hostile mood of customers, leading to customer dissatisfaction regardless of the performance of the core tasks of the services delivered to fulfill customer needs (Yee et al., 2008).

Service employees with a high level of job satisfaction will appear to the customer to be more balanced and pleased with their environment, leading to a positive influence on the level of customer satisfaction. In contrast, dissatisfied service employees are likely to display unpleasant emotions to customers, reducing the level of customer satisfaction through emotional contagion. Employee satisfaction has a long-term financial impact on the business - there is a link between employee satisfaction and customer satisfaction and its various outcomes, such as customer loyalty and profitability. Highly satisfied customers of a company are likely to purchase more frequently, in greater volume and buy other goods and services offered by the same service provider (Yee et al., 2008).

\subsubsection{Factors affecting job satisfaction}

An employee's overall satisfaction with the job is a result of a combination of factors. Financial compensation is only one of them and research suggests that other factors have a more important role (Ashton, 2018). The employee's overall satisfaction depends on working conditions, the opportunity for advancement, workload and stress level, financial and non-financial rewards, and several others.

Working conditions - since employees spend a lot of time at their workplace, companies should try to optimize working conditions. Such things as providing spacious work areas rather than cramped ones, adequate lighting and comfortable work stations contribute to favourable work conditions (Tutuncu and Kozak, 2007). The study of Laškarin Azić (2017) made on the sample of employees working in the Croatian hospitality industry show that there is a direct relationship between employee satisfaction with co-worker relationships and job satisfaction, but also an indirect relationship with employee hospitality.

Opportunity for advancement - employees are more satisfied with their current job if they see a path available to move up the ranks in the company and be given more responsibility and higher compensation (Tutuncu and Kozak, 2007).

Workload and stress level - dealing with a workload that is far too heavy and deadlines that are impossible to reach can cause job satisfaction to erode for even the most dedicated employee. Falling short of deadlines results in conflict between employees and supervisors and raises the stress level of the workplace. Many times, this environment is caused by ineffective management and poor planning (Tutuncu and Kozak, 2007).

Financial and non-financial rewards - job satisfaction is impacted by an employee's views about the fairness of the company wage scale as well as the current compensation received. Opportunities to earn special incentives, such as bonuses, extra paid time off or vacations, also bring excitement and higher job satisfaction to the workplace (Tutuncu and Kozak, 2007).

\subsection{Corporate social responsibility}

Many researchers have identified several dimensions of social responsibility that occur in different economic activities. These dimensions relate to the environment, human resources, the local community, employees, business performance, etc. (Ahmad et al., 2003; Khasharmeh and 
Desoky, 2013; Lipunga, 2013; Ponnu and Okoth, 2009). The European Union has also recognized the importance of corporate social responsibility, and in 2001 the European Commission issued a Green Paper on corporate social responsibility to launch a wide-ranging debate on this topic at national and international level.

Social responsibility is also highlighted by the international non-profit organization Global Reporting Initiative (GRI), which has developed a framework for reporting on sustainable development. The guidelines dictate three dimensions of reporting; economic, environmental, and social category (GRI, 2020). There is an increase of reports about corporate social responsibility as more and more stakeholders expect information on the socially responsible operation of a company (De Grosbois, 2012).

In 2014, the Council of the European Union adopted an amended Directive on the disclosure of non-financial information of certain large companies. The amendments must be considered by companies with more than 500 employees. Companies must prepare a description of policies, results and risks related to environmental protection, social responsibility and treatment of employees, respect for human rights and anti-corruption and bribery. The amended directive must be taken into account by companies in their annual reports from 2018 onwards (Directive 2014/95/EU).

Social responsibility in the hotel industry has not been of interest to researchers for a long time. However, this has changed considerably, especially in the last decade, with more research on the implementation of socially responsible behaviour in the hotel industry (Kim et al., 2019). The most common dimensions of corporate social responsibility in the hotel industry are local communities, the environment, human resources, and market policy (De Grosbois, 2012; Holcomb et al., 2007; Garay and Font, 2012; Tsai et al., 2012, Benavides-Velasco et al., 2014; Su et al., 2017). In terms of reporting, further studies are needed to explore the actual levels of information quality disclosed in corporate social responsibility reports (Serra-Cantallops et al., 2018).

\section{INDICATORS INCLUDED IN THE DEVELOPED PERFORMANCE MEASUREMENT SYSTEM}

When considering the indicators that should be included in the benchmarking software, the authors of the software tried to include as many dimensions as possible. However, not all of the indicators that were identified in the literature as important could be included, since this would result in too extensive amount of data that hotels should prepare as inputs for the benchmarking system. Based on the theoretical review and the discussion with hotel representatives, the following indicators were defined as the most important and as such are included in the software. First, we present the indicators regarding guest segmentation.

Room occupancy rate by (monthly data):

- Marketing distribution channels (individuals, groups, allotments, others),

- Day of the week (separately for each day of the week).

Indicators about guests by (monthly data):

- Their motive of stay (leisure, business, congress, other),

- Frequency. 
Questionnaire for the management about (annual data):

- Importance of different marketing media (for each media, importance is expressed in $\%$,

- Usage frequency of different marketing media (in \%).

In accordance with accounting standards and the USALI a set of non-financial indicators and selected financial indicators regarding employees was included in the system. Financially oriented information about employees is the following (monthly level):

- cost of employees per available room (gross salaries / available rooms),

- cost of employees (including outsourcing) per available room (gross salaries + cost of outsourcing / available rooms),

- value added per employee (number of employees is expressed by using effective hours),

- revenues per employee,

- GOP per employee.

On the annual level, apart from the above-mentioned indicators, we also monitor the following indicators:

- cost of education per employee, and

- share of employees that had quit the job.

Annually, employees are supposed to fill out a questionnaire that measures their satisfaction. An employee's overall satisfaction with the job is a result of a combination of factors. Financial compensation is only one of them. The employee's overall satisfaction depends on working conditions, opportunity for advancement, workload and stress level, financial and non-financial rewards, and several others. The questionnaire was composed using a combination of questions already used by Gu and Siu (2008) and Chi and Gursoy (2009).

The questions are the following:

- How satisfied are they with their job (Chi and Gursoy, 2009);

- How satisfied are they with the salary (Gu and Siu, 2008);

- How satisfied are they with the remuneration system (Gu and Siu, 2008);

- How efficient is the training system (Gu and Siu, 2008);

- How often do they evidence stress at their workplace (Gu and Siu, 2008);

- Do they intend to work for the company for a long time (Chi and Gursoy, 2009).

For all the questions, a 5-point Likert scale is used. The questionnaire also includes some questions about demographic data.

Based on the literature review and feedback of hotel representatives, we created a set of indicators for measuring the social responsibility of an individual hotel. The selection of indicators was based on the most frequently defined dimensions of corporate social responsibility in the hotel industry and on the recommendations of the European Commission. The dimension of the local community is monitored with the indicator that measures the share of donations in relation to gross operating profit (GOP). The environmental dimension is covered with several indicators such as water usage per occupied and available room, electricity usage per occupied and available room, oil usage per occupied and available room, gas usage per occupied and available room, share of investments into energy efficiency of buildings in GOP and share of costs of printed promotional materials in GOP. The dimension of marketplace policy is covered with 
the liabilities turnover ratio indicator. Moreover, representatives of the hotels have to fill out the questionnaire about CSR concerning activities about separating all types of waste, recycling (reuse within the company, e.g. wastewater, paper), energy savings (electricity, heating/cooling), financial assistance for activities and projects in the local community (sponsoring of local sports clubs, charitable contributions, etc.), cooperation with local producers. This questionnaire aims to raise the company's efforts regarding CSR activities. The framework of the developed performance measurement system is shown in figure 1 .

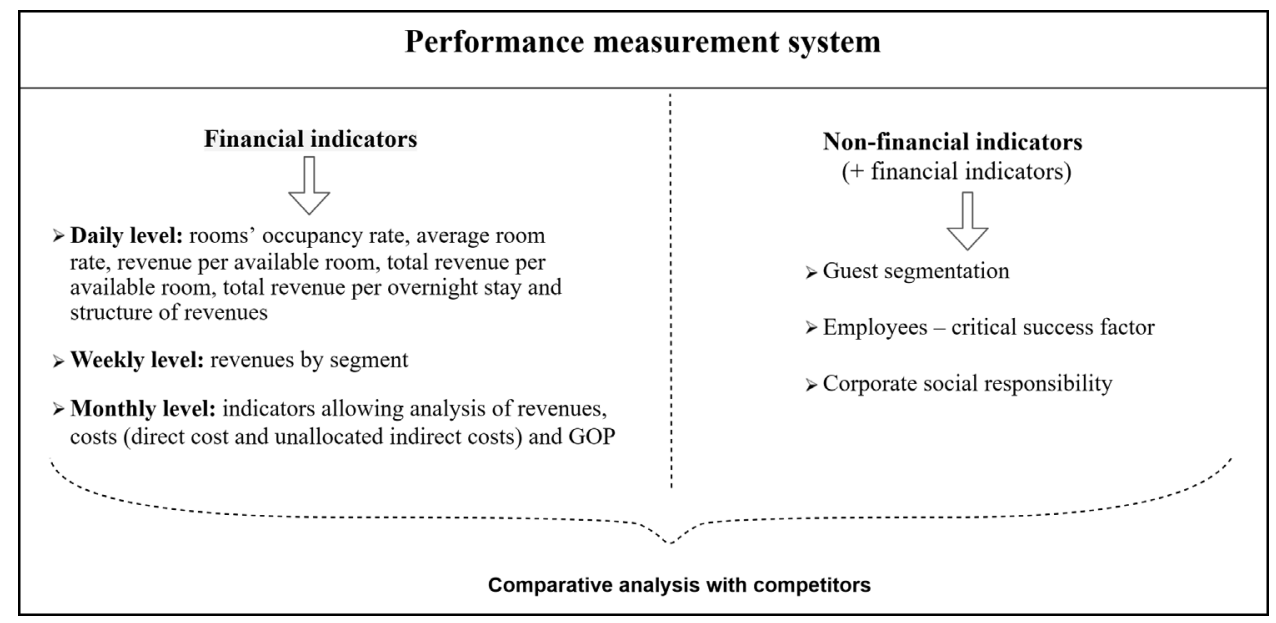

Figure 1. Framework of the developed performance measurement system

\section{APPLICATION IN PRACTICE AND FUTURE RESEARCH DIRECTIONS}

Based on the presented data, the user of this performance measurement system can choose the desired set of benchmarks. The user must choose at least three other hotels (from among those using the software). The selection is based on the number of rooms and/or type of the hotel and/or number of stars, or some other general characteristic of the hotel. The selection process does not allow choosing other hotels by their names, but the benchmarks must be selected based on characteristics of interest (number of rooms, number of stars, etc.). After selecting the benchmarks, the user has the chance to compare its own results to the lowest, highest, and the average value of chosen benchmarks. The important feature of the system is that it performs the comparison and shows to the user results only if the user uploads its own data. Unless the hotel uploads its own results, it will not have the chance to see the results of the competitors.

The project founding has served to develop the performance measurement methodology. The result of the presented project is a performance measurement tool for daily, monthly, and annual monitoring and comparison of hotel operations. This performance measurement system compares internal achievements of hotels, according to the same criteria and considering international reporting standards in the hotel industry, as well as modern management concepts and best practices.

The intention of the authors is to implement the presented benchmarking performance measurement system by Slovene and Croatian hotel companies. The performance measurement system, based on financial indicators, is currently used by 112 hotels in Croatia (FTHM, 2020). These companies use the USALI standards and regularly send daily and monthly business data, and in return receive reports with key business indicators for a pre-determined comparative set. The benchmarking analysis is provided daily. 
Data confidentiality is ensured as only the highest, lowest, and mean values of indicators for the selected sample of hotels are displayed. Indicators of the selected comparative set of competitors are shown only if at least three hotels are involved. This benchmarking system allows comparison of hotels based on different indicators; individual hotels can thus identify their strengths and weaknesses and receive information for revenue and cost management.

In Slovenian hotels, the implementation was not that successful, as the financial reporting system is basically different and the required adjustments to the accounting records are more numerous and consequently lead to higher costs. We assume that the interest in introducing the aforementioned business performance measurement system will be greater when Slovenian companies will implement the concept of USALI standards in monitoring the performance of individual hotels.

For hotel companies to be successful and stay competitive, they need to adapt to changes required by the market. In this sense, it is necessary to continuously seek good business practices that will also enable the achievement of the best business results. These continuous improvements are also carried out based on positive as well as negative experiences of others, to improve one's own business. Benchmarking can be of great help to businesses in this process. In this regard, data of own operations, without placing them in the context of hotels from the same region and/or of similar characteristics, are not a sufficient basis for a realistic analysis of the hotel's position, analysis of strengths and weaknesses in relation to competition and for strategic decision-making purposes. The possibility to solve this problem is the introduction of modern and innovative solutions for monitoring, measuring, and comparing business results. Köseoglu et al. (2020) found that managers in hotels prioritize monitoring competitors' behaviours and macro-environmental characteristics over internal analysis of the company when formulating business strategies.

Limitations of the presented performance measurement system refer to the number of indicators included. Even though the authors of the methodology and future users from hotels are aware that many other indicators could be included in the software, the authors were obliged to decide between the level of functionality and the amount of information provided. Representatives of the hotels emphasized that the transmission of data should not take too much time.

Future research could expand to new markets where the hotel companies do not use performance measurement systems which allow them to compare performance with their competitors. Future research could also address particularities of the hotel industry in other countries and develop a suitable methodology for measuring performance in these markets.

\section{CONCLUSION}

The purpose of the presented performance measurement system developed for Slovene and Croatian hotels is to enable the management of these hotels to perform a benchmarking analysis on time. This benchmarking system provides a prompt comparative analysis with competitors and enables timely corrective actions when inefficiencies are discovered. The system gives a unique possibility to make comparative analyses with similar hotels. The developed performance measurement system provides selected results of hotels' performance on a daily, monthly, and annual level and thus provides a basis for benchmarking analysis. 
Slovene hotels still do not monitor their performance based on USALI standards. USALI provides a base for detecting the existing state of performance and moreover renders possible a comparative analysis with international competitors. Since the methodology of financial indicators used in the presented performance measurement system is based on USALI standards, Slovene hotels have the opportunity to monitor their performance according to internationally recognized standards in the hotel industry. This kind of performance measurement system is especially necessary for Slovenian hotels since on average they do not generate value for their owners. Even though statistical data about tourist arrivals and overnight stays are satisfactory, many hotels in the region are not successful. The proposed performance measurement system can help them in solving this issue.

Problems faced by hotels in both countries are reflected in large differences in methods of internal monitoring and measurement of business results, the absence of a system for measuring social responsibility indicators, non-implementation of performance measurement systems with financial and non-financial business indicators and incomplete implementation of financial reporting standards USALI. The implementation of USALI is especially important so that hotels can be compared with each other, both at the local level and internationally.

\section{REFERENCES}

Ahmad, Nik N. N., Sulaiman, M., \& Siswantoro, D. (2003). Corporate Social Responsibility Disclosure in Malaysia: An Analysis of Annual Reports of KLSE Listed Companies. International Journal of Economics, Management and Accounting, 11(1), 1-21.

AJPES. (2020). Financial data. Retrieved from https://www.ajpes.si/fipo/ag_default.asp.

Arbelo, A., Pe'rez-Go'mez, P., Arbelo-Pe'rez, M. (2017). Cost efficiency and its determinants in the hotel industry. Tourism Economics, 23(5) 1056-1068.

Ashton, A. S. (2018). How human resources management best practice influence employee satisfaction and job retention in the Thai hotel industry. Journal of human resources in hospitality \& tourism, 17(2), 175-199.

Benavides-Velasco, C.A., Quintana-García, C., \& Marchante-Lara, M. (2014). Total quality management, corporate social responsibility, and performance in the hotel industry. International Journal of Hospitality Management, 41, 77-87.

Casado-Díaz, J. M., \& Simón, H. (2016). Wage differences in the hospitality sector. Tourism Management, 52, 96-109.

Chibili. M. N. (2016). Basic Management Accounting for the Hospitality Industry. Noordhoff Uitgevers Groningen: Houten.

Chi, C. G., \& Gursoy, D. (2009). Employee satisfaction, customer satisfaction, and financial performance: An empirical examination. International Journal of Hospitality Management, 28(2), 245-253.

Damonte, L., Rompf, P., Bahl, R., \& Domke, D. (1997). Brand affiliation and property size effects on measures of performance in lodgings industry. Hospitality research journal, 20(3), 1-16.

De Grosbois, D. (2012). Corporate Social Responsibility Reporting by the Global Hotel Industry: Commitment, Initiatives and Performance. International Journal of Hospitality Management, 31(3), 896-905.

Dopson, L.R., \& Hayes, D.K. (2016). Managerial Accounting for the Hospitality Industry. New Baskerville: Wiley. 
Dent, J. (1996). Global competition: challenges for management accounting and control. Management accounting research, 7(2), 247-269.

Directive 2014/95/EU of the European Parliament. (2014). Retrieved from https://eur-lex.europa. eu/legal-content/EN/TXT/?uri=CELEX\%3A32014L0095.

Downie, N. J. (1997). The use of accounting information in hotel marketing decisions. International journal of hospitality management, 16(3), 305-312.

D’Urso, P., De Giovanni, L., Disegna, M., \& Massari, R. (2013). Bagged Clustering and its application to tourism market segmentation. Expert Systems with Applications, 40(12), 4944-4956.

Forgacs, G. (2010). Revenue Management. Maximizing Revenue in Hospitality Operations. Michigan: American Hotel and Lodging Educational Institute.

FTHM - Faculty of Tourism and Hospitality Management. (2020). Hotel Benchmarking. Retrieved from http://www.hotel-benchmarking.com/uploads/44383-benchmarking-report-for-12-2020.pdf

Füller, J., \& Matzler, K. (2007). Virtual product experience and customer participation-A chance for customer-centred, really new products. Technovation, 27(6-7), 378-387.

Garay, L. A., \& Font, X. (2012). Doing Good to Do Well? Corporate Social Responsibility Reasons, Practices and Impacts in Small and Medium Accommodation Enterprises. International Journal of Hospitality Management 31(2), 329-337.

GRI. (2020). GRI Standards. Retrieved from https://www.globalreporting.org/how-to-use-thegri-standards/resource-center/?g=6fac477e-42a6-42b4-b2b5-dc34887703d5.

Gu, Z., \& Siu, R. C. S. (2008). Industry Labor Force Quality: An Investigation from the Customer Service Perspective. UNLV Gaming Research and Review Journal, 12(1-2), 1-13.

Harris, P. J. (1992). Profit planning. Oxford: Butterworth-Heinemann.

Holcomb, J. L., Randall, S.U., \& Okumus, F. (2007). Corporate Social Responsibility: What Are Top Hotel Companies Reporting? International Journal of Contemporary Hospitality Management, 19(6), 461-475.

Ivankovič, G., Jerman, M., Planinc, T., \& Uran Maravić, M. (2015). Benchmarking of the Slovene and Croatian hotel industry - approach to market segmentation and employees. In C. Kerdpitak (Ed.), ICBTS 2015: Proceedings of the 2015 ICBTS International Academic Research Conference in Europe \& America. Paper presented at International Academic Research Conference, Paris, France, 12-15 April, 2015 (pp. 83-90). Bangkok: ICBTS Institute \& CK Research.

Jones, T. A. (1995). Identify Managers Information Needs in Hotel Companies. In P. J. Harris (Ed.), Accounting and Finance for the International Hospitality Industry (pp. 163-182). Oxford: Butterworth-Heinemann.

Jones, T. A, \& Lockwood, A. (1998). Operations management research in the hospitality industry. International journal of hospitality management, 17 (2), 183-202.

Kahreh, M. S., Tive, M., Babania, A., \& Hesan, M. (2014). Analyzing the Applications of Customer Lifetime Value (CLV) based on Benefit Segmentation for the Banking Sector. Procedia - Social and Behavioral Sciences, 109(8), 590-594.

Kaplan, R. S., \& Norton, D. P. (1992). The Balanced Scorecard: Measures that Drive Performance. Harvard Business Review, 70, 71-79.

Khasharmeh, H.A., \& Desoky, A. M. (2013). On-line Corporate Social Responsibility Disclosures: The Case of the Gulf Cooperation Council (GCC) Countries. Global Review of Accounting and Finance, 4(2): 39-64.

Kim, Y. H., Barber, N., \& Kim, D. (2019). Sustainability research in the hotel industry: Past, present, and future. Journal of Hospitality Marketing \& Management, 28(5), 576-620. 
Köseoglu, M. A., Altin, M., Chan, E., \& Aladag, O. F. (2020). What are the key success factors for strategy formulation and implementation? Perspectives of managers in the hotel industry. International Journal of Hospitality Management, 89, 102574.

Laškarin Ažić, M. (2017). The impact of hotel employee satisfaction on hospitability performance. Tourism and Hospitality Management, 23(1), 105-117.

Lewis, R., \& Chambers, R. E. (1989). Marketing leadership in hospitality. Foundations and practices. London: Van-Nostrand Reinhold.

Lipunga, A. M. (2013). Corporate Social Responsibility Reporting by Commercial Banks in Annual Reports: Evidence from Malawi. International Journal of Business and Social Research, 3(9), 88-101.

Matzler, K., \& Renzl, B. (2007). Assessing asymmetric effects in the formation of employee satisfaction. Tourism Management, 28(4), 1093-1103.

Mia, L., \& Chenhall, R. (1994). The usefulness of MAS functional differentiation and management effectiveness. Accounting, organization, and society, 19(1), 1-13.

Ministry of Tourism Republic of Croatia. (2020). Tourism in figures 2019. Retrieved from https:// www.htz.hr/sites/default/files/2020-07/HTZ\%20TUB\%20HR_\%202019\%20\%281\%29.pdf.

Nemec Rudež, H. (2013). Potovalna dejavnost v sodobnem okolju. Koper: University of Primorska.

Nemec Rudez., H., \& Mihalic, T. (2007). Intellectual capital in the hotel industry: A case study from Slovenia. Hospitality Management, 26(1), 188-199.

Nickels, G. W., \& Wood B. M. (2000). Marketing Relationships, Quality, Value. New York: Worth Publishers, Inc.

Polovitz, N. (1996). Foundations of tourism. Chicago: Prentice Hall.

Ponnu, C. H., \& Okoth, M. O. (2009). Corporate Social Responsibility Disclosure in Kenya: The Nairobi Stock Exchange. African Journal of Business Management, 3(10), 601-608.

RNUST 2007-2011. (2009). Retrieved from http://www.turistica.si/downloads/ RNUST-2007-2011.pdf.

Serra-Cantallops, A., Peña-Miranda, D. D., Ramón-Cardona, J., \& Martorell-Cunill, O. (2018). Progress in Research on CSR and the Hotel Industry (2006-2015). Cornell Hospitality Quarterly, 59(1) 15-38.

STB - Slovenian Tourist Board. (2020). Tourism in numbers 2019. Retrieved from https://www. slovenia.info/uploads/dokumenti/tvs/2019/turizem_v_stevilkah_2019.pdf.

Stubelj, I. \& Jerman, M. (2019). Empirical analysis of Slovenian hotel industry performance with the relative residual income approach. In V. Bevanda \& S. Stetić (Eds.), 4th International Thematic Monograph: Modern Management Tools and Economy of Tourism Sector in Present Era (pp. 397-412). Belgrade: Association of Economists and Managers of the Balkans with Faculty of Tourism and Hospitality, Ohrid, North Macedonia.

Su, L., Pan, Y., \& Chen, X. (2017). Corporate social responsibility: Findings from the Chinese hospitality industry. Journal of Retailing and Consumer Services, 34, 240-247.

USALI - Uniform System of Accounts for the Lodging Industry. (2019). Retrieved from https:// www.hftp.org/hospitality_resources/usali_guide/

Tkaczynski, A., Rundle-Thiele, S. R., \& Beaumont, N. (2009). Segmentation: A tourism stakeholder view. Tourism Management, 30(2), 169-175.

Tranter, K. A., Stuart-Hill, T., Parker, J. (2014). An Introduction to Revenue Management for the Hospitality Industry: Principles and Practices for the Real World. Harlow: Pearson.

Tsai, H., Nelson, K. F. T., \& Cheng, S. (2012). Hotel Employees' Perceptions on Corporate Social Responsibility: The Case of Hong Kong. International Journal of Hospitality Management, 31(4), 1143-1154. 
Tutuncu, O., \& Kozak, M. (2007). An Investigation of Factors Affecting Job Satisfaction. International Journal of Hospitality and Tourism Administration, 8(1), 1-19.

Yee, R. W. Y., Yeung, A. C. L., \& Cheng, T. C. E. (2008). The impact of employee satisfaction on quality and profitability in high-contact service industries. Journal of Operations Management, 26(5), 651-668.

WTTC - World Travel \& Tourism Council. (2020). Slovenia. 2020 Annual Research: Key Highlights. Retrieved from https://wttc.org/Research/Economic-Impact 